\title{
SISTEMÁTICA PARA ANÁLISE DE RISCO DE SAÚDE E SEGURANÇA DO TRABALHO EM ESTAÇÕES ELEVATÓRIAS DE ÁGUA
}

\section{SYSTEMATIC OCCUPATIONAL SAFETY AND HEALTH RISK ANALYSIS IN PUMPING STATIONS OF WATER}

\author{
Giseli Lopes Correia Cavalcanti ${ }^{\star}$ E-mail: giselilccavalcanti@gmail.com \\ Eliane Maria Gorga Lago* E-mail: elianelsht@poli.br \\ Béda Barkokébas Junior* E-mail: beda.jr@upe.br \\ *Universidade de Pernambuco (UPE), Recife, PE
}

\begin{abstract}
Resumo: O estudo propõe a identificação, avaliação e recomendações de controle dos riscos ocupacionais encontrados nas Estações Elevatórias de Água. Desta forma, foram realizadas visitas nas instalações escolhidas como objeto de estudo, posteriormente os agentes e os riscos foram identificados, avaliados e classificados em graus que variam de "irrelevante", "relevante", "de atenção", "crítico" e "emergencial", e por fim foram propostas medidas de tratamento para controle, minimização e eliminação dos riscos. Os dados foram obtidos em 10 (dez) Estações Elevatórias de Água, onde os operadores realizavam as atividades identificadas Posteriormente, os riscos identificados, choque elétrico, queda, picada de animais peçonhentos, prensamento, acidentes de trânsito e postura inadequada, foram avaliados e classificados de acordo com a gradação dos riscos. Foi possível concluir que as atividades realizadas nos ambientes estudados, bem como os próprios ambientes, geram riscos de segurança aos trabalhadores.
\end{abstract}

Palavras-chave: Estação Elevatória de Água. Análise de Avaliação dos Riscos. Saúde e Segurança do Trabalho.

Abstract: This study proposes the identification, evaluation and control of occupational hazards recommendations found in water pumping stations. Visits were held at the premises chosen as an object of study, then the agents and the risks have been identified, evaluated and classified into grades ranging from "irrelevant", "significant", "attention", "critical" and "emergency "and finally were proposed treatment measures to control, minimize and eliminate risks. The data were obtained in 10 Water Pumping Stations. Subsequently, the identified risks, electric shock, fall, bite of poisonous animals, pinch point, traffic accidents and improper posture were evaluated and classified according to the degree of risk. Was concludes that the activities performed in the study sites, as well as the environments themselves, generate safety risks to workers.

Keywords: Water Pumping Stations. Analysis Risk Evaluation. Occupational Safety and Health.

\section{INTRODUÇÃO}

sistema de saneamento básico é o conjunto formado pelos sistemas de abastecimento de água, sistema de esgotamento sanitário, gerenciamento de resíduos sólidos e drenagem de água de chuvas. Consistindo em um sistema que 
visa afastar, coletar, transportar, tratar e dispor sanitariamente o esgoto gerado pelas casas, pelo comércio e pelas indústrias (NUCASE, 2008).

Apesar dos avanços na tecnologia e da oferta de água do país, o acesso à água potável é o componente que mais impacta diretamente a qualquer população.

Assim como em qualquer outro ambiente de trabalho, os operadores das estações de tratamento de água estão expostos a agentes ambientais, que podem causar acidentes ou doenças, que podem ser desde a captação de água bruta nos mananciais até o fornecimento de água potável à população.

Apesar do tema abordado se tratar de uma discussão antiga, o sistema atual de abastecimento de água é bastante deficiente no que tange a tecnologia, construções e operacionalização, afetando, desta forma, a saúde e a segurança dos trabalhadores. Contudo, os acidentes nas unidades pertencentes ao Sistema de Abastecimento de Água - SAA não acontecem por acaso, eles, geralmente, são causados por indiferença, falta de atenção, negligência, falta de manutenção, ignorância, falta de cuidado, pouca iluminação, supervisão defeituosa, além de maus projetos e arranjos de equipamentos (OLIVEIRA, 2010).

Com vistas à execução de um ambiente de trabalho seguro e com qualidade, que possa ser oferecido aos trabalhadores do saneamento básico, através da operação de elevação de água, principalmente, no que tange ao serviço de abastecimento de água, é de grande importância um estudo que possa quantificar e qualificar tais riscos, além de propor diretrizes mínimas que ofereçam uma condição segura de trabalhos nestes ambientes.

Desta forma, esta pesquisa se justifica socialmente, contribuindo com o bem estar humano e na constância de uma sociedade produtiva; cientificamente promovendo a divulgação do conhecimento; tecnicamente, contribuindo na organização do sistema de gestão em segurança e saúde do trabalho neste setor; além de economicamente, diminuindo os gastos, visto que acidentes de trabalho geram custos econômicos.

O presente estudo tem por objetivo propor sistemáticas de análise de riscos dos ambientes das estações elevatórias de água utilizando a ferramenta para classificação de risco, preconizada pela AHIA (Association of Healthcare Internal Auditors), para identificar, avaliar e recomendar medidas de controle para os riscos ocupacionais classificados no ambiente de trabalho, através de estudo de campo. 


\section{ESTAÇÕES ELEVATÓRIAS DE ÁGUA}

Os sistemas de abastecimento de água são projetados para proporcionar o fornecimento contínuo de água com qualidade satisfatória e pressão suficiente a todos os consumidores (SANTOS; SOARES; SILVA, 2016).

Desta forma, Estação Elevatória de Água - EEA compreende o conjunto de edifícios, máquinas, equipamentos e aparelhos necessários para realizar a elevação da água (bruta ou tratada) de um ponto a outro, através de pressão e volume adequado (CHIARA, 1968). Sendo assim, tais conjuntos são destinados à elevação de água para os reservatórios que se encontram em locais de que necessitem de pressurização para serem abastecidos.

Oliveira (2010) conceitua estações elevatórias como o local onde ocorre o bombeamento ou o recalque da água já tratada, que está localizada em áreas mais baixas e deve ser bombeada para áreas mais altas ou para áreas que estão distantes da sua localização inicial.

\subsection{Tipos de Estações Elevatórias}

As Estações Elevatórias de Água podem ser classificadas de 3 (três) formas, quanto ao tipo de água que recalcam, a localização da bomba e características hidráulicas. Os tipos de Estações Elevatórias dependem de diversos fatores, como: localização do manancial e dos outros componentes do SAA, relevo e topografia do local destinado à instalação, volume de água recalcada, tipo de água, etc..

Quando são classificadas em função do tipo de água que bombeiam, Heller e Pádua (2006) classificaram as estações em: Estação Elevatória de Água Bruta (EEAB), quando recalcam água sem tratamento, e Estação Elevatória de Água Tratada (EEAT), quando recalcam a água que já passou pelas etapas do tratamento de água.

Contudo, quando estas são classificadas quanto à localização da bomba, Gurgel (2006) as classifica da seguinte forma: Estação Elevatória de Água de Poço Seco, quando as bombas de sucção estão alocadas fora da água, e Estação Elevatória de Água de Poço Úmido, quando as bombas estão alocadas dentro da água. 
No que diz respeito às características hidráulicas das Estações Elevatórias de Água, Heller e Pádua (2006) classificaram o sistema de transporte de água em: conduto livre, quando a água escoa sempre em declive, mantendo uma superfície livre sob o efeito da pressão atmosférica; conduto forçado por gravidade, quando a pressão interna permanentemente superior à pressão atmosférica permite à água mover-se, quer em sentido ascendente quer em sentido ascendente, pois existe a existência de um sistema de bombeamento, neste caso, a movimentação do líquido é realizada de forma mista, através do conjunto motobomba e da gravidade; e conduto forçado, quando o local da captação estiver em um nível inferior, que não possibilite a adução por gravidade, é necessário o emprego de equipamento de recalque (conjunto motor-bomba e acessórios) (SANESUL, 2011).

\subsection{Composição das Estações Elevatórias}

Para a implantação de um sistema de abastecimento de água bombeada devem ser levados em consideração os diversos elementos das unidades, tais como os dutos (tubulações) de bombeamento, os componentes hidráulicos e mecânicos, e as fontes de energia relacionadas à operação do sistema (MAHAR; SINGH, 2013).

Portanto, segundo Oliveira (2010) as estações elevatórias são compostas por casa de bombas (abrigo da bomba, motor e acessórios), reservatórios de água, poço de sucção e outros equipamentos, como tubulações e registros, que são utilizados para administrar as operações hidráulicas do sistema.

A casa de bombas é definida como uma edificação destinada ao abrigo dos conjuntos motobomba e seus acessórios, possuindo iluminação e ventilação adequadas, espaço dimensionado de forma suficiente que proporcione segurança na execução das atividades, segurança na instalação e movimentação dos conjuntos elevatórios, abrangendo espaço para os componentes elétricos, como quadros de comando e chaves (SANESUL, 2011).

Sendo assim, as dimensões destes espaços devem ser instaladas permitindo facilidade para locomoção, manutenção, montagem, desmontagem, entrada e saída dos equipamentos, bem como, assegurar o abrigo dos dispositivos para os serviços para execução de manobras e a segura movimentação nas unidades instaladas (TSUTIYA, 2006). 
As bombas, abrigadas nesses espaços são os equipamentos encarregados de realizar a sucção da água do reservatório (poço) de sucção e pressurizar a mesma através do rotor, impulsionando-a para o reservatório ou ponto de recalque (SANESUL, 2011).

Segundo Gurgel (2006), devido ao maior rendimento associado ao menor custo de instalação bem como a melhor operação e manutenção, as bombas centrífugas são as mais encontradas em estações elevatórias, pois leva em consideração também o fornecimento da eletricidade para o motor elétrico.

Contudo, para que o sistema de bombeamento de água funcione de forma eficiente é essencial que seja realizada a seleção adequada de tecnologia e tamanho destes componentes (RAWAT; KAUSHIK; LAMBA, 2016).

Portanto, em caso de ausência de armazenamento hidráulico (reservatório de água) ou mesmo quando este é dimensionado erroneamente, não podendo comportar a quantidade de água ofertada pelo sistema, o excedente pode ser perdido caso a tecnologia de bombeamento implantada não seja adequada (BOUTELHIG; ARAB; HANINI, 2016). Visto que, grande parte do controle dos sistemas de bombeamento, no Brasil, é realizada de forma manual, fazendo-se a necessidade da adequada capacitação e atenção dos operadores para evitar desperdícios e mau uso dos sistemas.

Quanto às tubulações presentes nas Estações Elevatórias de Água são formadas por um conjunto de canalizações e equipamentos que realizam 0 transporte da água. Desta forma estas podem ser de sucção e de recalque (SANESUL, 2011; TSUTIYA, 2006), conforme descritas abaixo:

- tubulações de sucção: conjunto de canalizações e peças que vão do poço de sucção ou reservatório inferior até a entrada da bomba. Tal instalação se caracteriza por estar localizada antes da bomba;

- tubulações de recalque: conjunto de canalizações e peças que vão da saída da bomba até o reservatório superior ou ponto de recalque. Tal instalação se caracteriza por estar localizada após a bomba.

Segundo a SANESUL (2011) o poço de sucção de uma estação é o reservatório inferior do qual a água será recalcada, com capacidade ou volume estabelecido de maneira a assegurar a regularidade no trabalho de bombeamento. 
Tal instalação é considerada uma estrutura de transição, pois recebe a água afluente e a coloca à disposição do sistema que realiza o bombeamento, devendo possuir facilidade no acesso e limpeza, bem como, possuir estrutura composta de paredes verticais e de laje de fundo contendo inclinação que favoreça o sentido de da sucção das bombas.

\subsection{Saúde e segurança do trabalho em estações elevatórias}

Segundo Kohlman Rabbani et al (2011) as sistemáticas que visam avaliar os riscos de saúde e segurança do trabalho devem procurar apresentar não apenas um diagnóstico do posto de trabalho analisado, mas, além disso, buscar o estabelecimento de sistemas, os quais baseados em parâmetros estatísticos, possam auxiliar na proposição de medidas de prevenção e proteção projetadas adequadamente para salvaguardar a segurança e saúde dos trabalhadores.

Desta forma, Hernandez e Mac (2016) afirmam que as atividades realizadas em estações de tratamento podem gerar riscos aos trabalhadores em manutenções e operações com os equipamentos de instalações de distribuição de água, devendo assim, utilizar técnicas para controlar e prevenir riscos de choques elétricos.

Além disso, para Barkokébas Junior et al (2010) há ainda deficiências no que se refere ao projeto de layout das estações elevatórias de água voltado à área de saúde e segurança do trabalho, destacando-se entre eles a ausência de isolamento acústico adequado na sala de descanso do trabalhador.

Assim, como agravante, Cruz, Lago e Barkokébas Junior (2013) afirmam que os operadores destes ambientes que estão expostos a altos níveis de pressão sonora podem, ao longo dos anos, sofrer perda auditiva neurossensorial irreversível, devido à exposição a níveis elevados de ruído durante as atividades laborais.

Lago et al (2008) apresentam um sistema para implantação de indicadores de saúde e segurança do trabalho como uma ferramenta capaz de contribuir na adequada e efetiva estruturação de sistemáticas para análise dos riscos.

\subsection{Ferramenta de avaliação de risco}

A Análise Preliminar de Riscos (APR) é uma ferramenta de avaliação de risco Revista Produção Online, Florianópolis, SC, v. 17, n. 1, p. 108-132, jan./mar. 2017. 
bastante utilizada em estudos críticos a cerca da segurança de determinado sistema, principalmente, na fase preliminar da concepção do sistema, determinando os cenários de possíveis acidentes, utilizando para isso as variáveis de probabilidades de ocorrência (frequência) e gravidade das consequências, com a finalidade de propor soluções preventivas ou protetivas, e consequentemente, reduzir o nível de risco (GUENAB; BOULANGER; SCHÖN, 2013).

A APR tem como objetivo fornecer dados para a eliminação de vários eventos iniciais e informações para a implementação de sistemas de segurança na fase conceitual, buscando atuar na segurança do trabalho através de um processo de desenvolvimento com as análises de segurança determinista e probabilística, gerando dados, particularmente, flexíveis, com capacidade de auditoria e resolução de resultados (McCARROLL et al., 2016).

Além disso, as ferramentas para a realização das análises de riscos foram desenvolvidas com a fim de criar subsídios que facilitacem a tomada de decisões, utilizando-se como base para um levantamento da gravidade e da severidade dos riscos existentes em determinando ambiente ou atividade, para que se evitasse im impactos negativos que os riscos ocupacionais podem gerar sobre pessoas, meio ambiente e instalações (ANTÃO, 2014).

Seguindo estes conceitos, Braga (2007) determinou alguns fatores que devem ser levados em consideração na elaboração de uma APR, tais como: rever problemas conhecidos; revisar os objetivos, as principais funções e procedimentos, bem como, os ambientes onde se darão as operações; determinar os riscos principais, com potencial para causar lesões; revisar os meios de eliminação ou controle dos riscos; e indicar os responsáveis pelas ações corretivas.

Com base no disposto acima, para o desenvolvimento da APR, a graduação dos riscos é realizada com base na ferramenta para classificação dos riscos preconizada pela Association of Healthcare Internal Auditors - AHIA, a qual tem como vantagem a determinação da classificação do risco em função dos efeitos que causam a saúde e da exposição. Além disso, baseada na ação dos agentes e condições do ambiente de trabalho os riscos são graduados conforme o quadro 1. 
Quadro 1- Graduação dos riscos

\begin{tabular}{|c|c|c|}
\hline CATEGORIA & DESCRIÇÃO \\
\hline $\begin{array}{c}\text { IRRELEVANTE } \\
\text { (controle de rotina) }\end{array}$ & $\begin{array}{c}\text { O agente não representa risco potencial de danos à saúde e/ou } \\
\text { integridade física. Ou quando ocorrem situações de desconforto } \\
\text { desprezível. Nesta categoria, o agente se encontra sob controle } \\
\text { técnico e abaixo do NA - Nível de Ação. }\end{array}$ \\
\hline RELEVANTE & $\begin{array}{c}\text { Existe um risco baixo a saúde, porém não causa efeitos agudos. } \\
\text { Nesta categoria, a exposição se encontra sob controle técnico no } \\
\text { NA - Nível de Ação. }\end{array}$ \\
\hline $\begin{array}{c}\text { DE ATENÇÃO } \\
\text { (monitoramento) }\end{array}$ & $\begin{array}{c}\text { Existe um risco moderado a saúde, porém não causa efeitos } \\
\text { agudos. Nesta categoria, a exposição se encontra sob controle } \\
\text { técnico e acima do NA - Nível de Ação, porém abaixo do LT - } \\
\text { Limite de Tolerância. }\end{array}$ \\
\hline $\begin{array}{c}\text { CRÍTICA } \\
\text { (controle primário) }\end{array}$ & $\begin{array}{c}\text { O agente é capaz de causar efeitos agudos à saúde do trabalhador } \\
\text { exposto. Nesta categoria, a exposição não se encontra sob controle } \\
\text { técnico, estando acima do LT - Limite de Tolerância. }\end{array}$ \\
\hline $\begin{array}{c}\text { EMERGENCIAL } \\
\text { (controle de urgência) }\end{array}$ & $\begin{array}{c}\text { O agente é capaz de causar efeitos agudos à saúde, além disso, as } \\
\text { práticas operacionais e/ou situações ambientais indicam aparente } \\
\text { descontrole da exposição. Situações de risco grave e iminente. }\end{array}$ \\
\hline
\end{tabular}

Fonte: AHIA (2014)

A classificação qualitativa da exposição dos trabalhadores é realizada conforme o quadro 2. Além da classificação da exposição é realizada da mesma forma a classificação dos efeitos a saúde, para isto será utilizado os parâmetros fixados no quadro 3. Desta forma, o quadro 4 serve de base para que seja determinada uma sequencia de forma que sejam elencadas quais medidas devem ser priorizadas.

Quadro 2 - Classificação Qualitativa da Exposição

\begin{tabular}{|c|c|c|}
\hline \multicolumn{2}{|r|}{ CATEGORIA } & DESCRIÇÃO \\
\hline 0 & NÃO HÁ EXPOSIÇÃO & Nenhum contato com o agente ou contato irrelevante. \\
\hline 1 & BAIXOS NÍVEIS & Contato não frequente com o agente. \\
\hline 2 & $\begin{array}{l}\text { EXPOSIÇÃO } \\
\text { MODERADA }\end{array}$ & $\begin{array}{c}\text { Contato frequente com o agente a baixas concentrações } \\
\text { ou não frequentes a altas concentracões. }\end{array}$ \\
\hline 3 & EXPOSIÇÃO ELEVADA & Contato frequente com o agente a altas concentrações \\
\hline 4 & $\begin{array}{l}\text { EXPOSIÇÃO } \\
\text { ELEVADÍSSIMA }\end{array}$ & $\begin{array}{c}\text { Contato frequente com o agente a concentrações } \\
\text { elevadíssimas }\end{array}$ \\
\hline
\end{tabular}

Fonte: AHIA (2014)

Quadro 3 - Classificação qualitativa de riscos à saúde

\begin{tabular}{|c|c|}
\hline CATEGORIA & EFEITOS A SAÚDE \\
\hline $\mathbf{0}$ & Efeitos reversíveis de pouca importância \\
\hline $\mathbf{1}$ & Efeitos reversíveis preocupantes \\
\hline $\mathbf{2}$ & Efeitos reversíveis preocupantes severos \\
\hline $\mathbf{3}$ & Efeitos irreversíveis preocupantes \\
\hline $\mathbf{4}$ & Ameaça a vida ou doença/lesão incapacitante \\
\hline
\end{tabular}

Fonte: AHIA (2014) 
Quadro 4 - Gradação de prioridade na avaliação qualitativa dos agentes

\begin{tabular}{|c|c|}
\hline EXPOSIÇĀO + EFEITO = CONTROLE & DESCRIÇÃO \\
\hline $0-1$ & Irrelevante \\
\hline $2-3$ & Relevante \\
\hline $4-5$ & De atenção \\
\hline $6-7$ & Crítica \\
\hline 8 & Emergencial \\
\hline
\end{tabular}

Fonte: AHIA (2014)

Os quadros 5 e 6, a seguir, são utilizados para interpretar e classificar os resultados quantitativos e se referem a valoração dos agentes ambientais e graduação da prioridade, proporcionando dessa forma maior suporte ao processo decisório nas medidas de Saúde e Segurança do Trabalho.

Quadro 5 - Valoração quantitativa dos agentes

\begin{tabular}{|c|c|}
\hline CLASSE DE RISCO & SITUAÇÃo REAL \\
\hline 1 & Inferior ao nível de ação \\
\hline 2 & Superior ao nível de ação \\
\hline 3 & Inferior ao Limite de Exposição \\
\hline 4 & Próximo ao limite de exposição \\
\hline 5 & Superior ao limite de exposição \\
\hline
\end{tabular}

Fonte: AHIA (2014)

Quadro 6 - Gradação da prioridade na avaliação quantitativa dos agentes

\begin{tabular}{|c|c|c|}
\hline CLASSE DE RISCO & GRAU & SITUAÇÃO REAL \\
\hline 1 & 1 & Irrelevante \\
\hline 2 & 2 & Relevante \\
\hline 3 & 3 & De Atenção \\
\hline 4 & 4 & Crítica \\
\hline 5 & 5 & Emergencial \\
\hline
\end{tabular}

Fonte: AHIA (2014)

\section{METODOLOGIA}

Trata-se de um estudo, com avaliação qualitativa e quantitativa dos principais riscos existentes no ambiente de trabalho em 10 (dez) estações elevatórias de água pertencentes ao sistema de abastecimento de uma prestadora de serviços no estado 
de Pernambuco. Além disso, a pesquisa é de caráter descritivo, pois descreveu as características deste ambiente, analisando a existência dos riscos ocupacionais e de que forma tais riscos podem ser minimizados seguindo os conceitos legais vigentes. Possui também caráter explicativo, identificando os fatores que determinam ou contribuem para a ocorrência destes elementos. Além disso, trata-se de uma pesquisa bibliográfica e documental, pois referencia os principais pontos tratados neste estudo e contribui como documento para conhecimento técnico, científico e estudos posteriores.

Desta forma, para viabilizar o desenvolvimento desta pesquisa, a metodologia foi estruturada em quatro etapas:

- a primeira etapa constituiu-se em pesquisas sobre o tema abordado, em periódicos, revistas, trabalhos acadêmicos e outras publicações, para elaboração do referencial teórico e dos aspectos introdutórios, juntamente com a justificativa e os objetivos deste trabalho;

- na segunda etapa foram escolhidas as 10 (dez) Estações Elevatórias de Água utilizadas como objeto de estudo, foram realizadas as visitas em campo para coleta de dados, imagens fotográficas e aplicação de check-list.. Além disso, foi realizado um diagnóstico, contendo todas as unidades, os riscos, as funções e os agentes, para identificação dos riscos, e servir e subsídio para criação um mapa de risco;

- na terceira etapa, os riscos encontrados na etapa antecedente, foram analisados e discutidos e posteriormente, foram definidas propostas de melhorias, levando em consideração os equipamentos, layout, gestão e projeto;

- na etapa final, foram discutidas as formas de controle dos riscos avaliados anteriormente de acordo com os preceitos legais avaliados.

As medidas de controle definidas devem ser aplicadas nas unidades de Estações Elevatórias de Água estudadas, contemplam prevenção e proteção. 


\section{RESULTADOS}

As Estações Elevatórias de Água do presente estudo se caracterizam por uma estrutura composta por 10 (dez) unidades sendo estas pertencentes ao mesmo grupo, que se localizam na região metropolitana do Recife, estado de Pernambuco. Tendo seu sistema composto por reservatórios, casa de bombas, sala do operador e tubulações de manobra.

A casa de bombas possui estrutura física composta de piso em granilite, acabamento de alvenaria em reboco pintado, teto do tipo laje concretada com cobertura de telha de fibrocimento, iluminação artificial (através de lâmpadas fluorescentes) e natural, ventilação apenas natural (através de portas e janelas), e pé direito com altura de aproximadamente 3,00 (três) metros.

A casa do operador faz parte da mesma edificação e possui as seguintes características em sua estrutura física, piso em granilite, acabamento de alvenaria em reboco pintado, teto do tipo laje concretada com cobertura de telha de fibrocimento, iluminação e artificial (através de lâmpadas fluorescentes) e natural, ventilação artificial (através de ventiladores) e natural (através de portas e janelas), e pé direito com altura de aproximadamente 3,00 (três) metros.

\subsection{Descrição das atividades nas unidades}

A partir das visitas realizadas foi possível identificar e descrever as atividades realizadas pelos operadores dos ambientes estudados, que são:

- realizar manutenção e limpeza da unidade: o funcionário realiza a limpeza da unidade, através de varrição e capinação, e dos equipamentos, com a finalidade de manter o bom funcionamento do sistema. Realiza a manutenção da unidade fazendo pequenos reparos, quando necessários, tanto nas instalaçoes da unidade como nos equipamentos que compõem as estações.

- receber e passa informações via rádio: o funcionário realiza comunicação com outras unidades operacionais através do rádio, quando necessário.

- realizar controle do nivel de reservatório: o funcionário verífica o nível de água dos reservatórios (semienterrado, apoiado e elevado) da unidade, além de 
controlar a entrada e a saída de água a fim de manter dentro do nível necessário.

- ligar e desligar o conjunto motobomba: o operador realiza o controle para operação dos conjuntos motor bomba (CMB) para adução da água (bruta e tratada) das unidades que fazem parte do sistema.

- realizar manobras de descarga ou abertura de registro: o funcionário realiza manobra de descarga para passagem da água para descarga de decantadores e filtros, bem como a abertura de registo atráves de manobras para distribuição da água.

- dirigir: o funcionário, em alguns casos, realiza serviços em mais de uma unidade, como operador volante. Nesse caso, o mesmo necessita utilizar o veículo da empresa para realizar as atividades.

Essas atividades foram descritas pelos operadores e ocorrem em todas as Estações Elevatórias de Água analisadas durante o presente estudo.

\subsection{Análise dos Riscos Ocupacionais}

$\mathrm{Na}$ avaliação de riscos, primeiramente, foram identificados os agentes existentes nas intalações das Estações de Elevatórias de Água (Quadro 7).

Quadro 7 - Agentes identificados nas unidades estudadas

\begin{tabular}{|c|c|}
\hline \multicolumn{2}{|c|}{} \\
\hline \multirow{2}{*}{ Acidente } & Chentes \\
\cline { 2 - 2 } & Que elétrico \\
\cline { 2 - 2 } & Picada de animais peçonhentos \\
\cline { 2 - 2 } & Prensamento \\
\cline { 2 - 2 } & Acidentes de trânsito \\
\hline Ergonômico & Postura inadequada \\
\hline Físico & Ruído \\
\hline Químico & Não identificado na atividade \\
\hline Biológico & Não identificado na atividade \\
\hline
\end{tabular}

Nas unidades pesquisadas foi levantado 0 quantitativo dos riscos identificados. Conforme figura 1, dentre as 10 (dez) unidades estudadas, em 9 (nove) foi possível encontrar os agentes ruído e choque elétrico, seguido de postura 
inadequada e queda encontrada em 8 (oito), e por último, picada de animais peçonhentos em 4 (quatro), prensamento em 3 (três) e acidentes de trânsito somente em 2 (duas).

Figura 1- Agentes identificados nas unidades estudadas

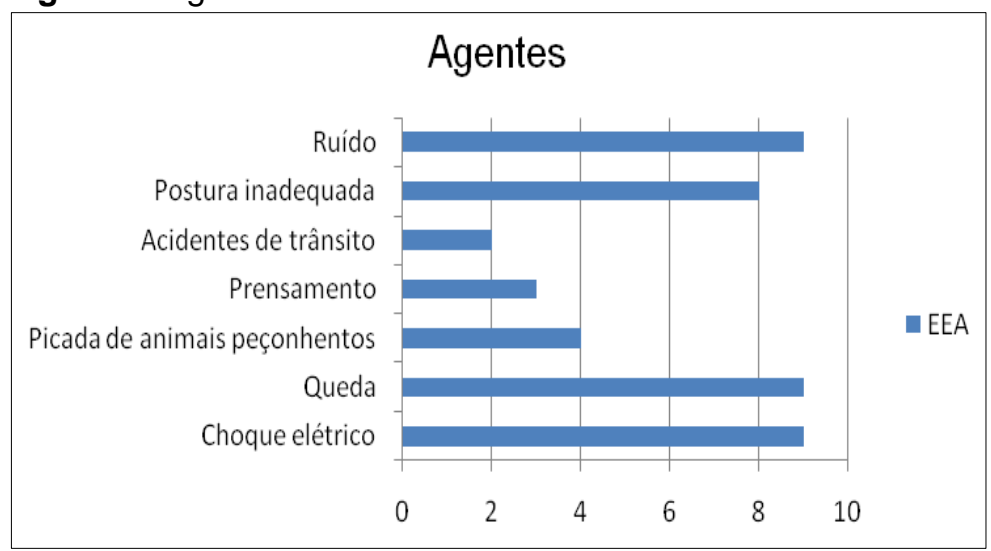

Apesar de ser qualificado em $90 \%$ das unidades, o agente ruído, não foi classificado como risco, pois após avaliação quantitativa, foi possível constatar que este agente se encontra abaixo do Nível de Ação (80 dB (A)) (Tabela 1).

Tabela 1 - Quantificação do agente ruído nas unidades

\begin{tabular}{ccc}
\hline Agente físico - Ruído & EEA & $\%$ \\
\hline Abaixo de $80 \mathrm{~dB}(\mathrm{~A})$ & 9 & 100 \\
$80 \mathrm{~dB}(\mathrm{~A})-85,0 \mathrm{~dB}(\mathrm{~A})$ & 0 & 0 \\
Acima do LT 85 dB (A) & 0 & 0 \\
\hline
\end{tabular}

Além do ruído, provocado pelas bombas responsáveis pela adução da água, se encontrar bem abaixo do Limite de Tolerância - LT descrito na NR 15 (85,0 $\mathrm{dB}(\mathrm{A}))$, os operadores de $40 \%$ das unidades, possuiam protetor aurícular tipo concha, disponibilizados pela empresa.

O risco de acidente choque elétrico também foi encontrado em $90 \%$ das unidades de EEA analisadas (Tabela 2). A partir da avaliação destes riscos, das 9 (nove) unidades pesquisadas, 2 (duas) foram classificados no grau "relevante', 4 (quatro) no grau "de atenção" e, 3 (três) no grau "crítico". 
Tabela 2 - Classificação do grau de risco do choque elétrico

\begin{tabular}{cccc}
\hline Grau de risco & EEA & $\%$ \\
\cline { 1 - 1 } Irrelevante & 0 & 0 \\
Relevante & 2 & 22,2 \\
De Atenção & 4 & 44,4 \\
Crítico & 3 & 33,3 \\
Emergencial & 0 & 0,0 \\
Total & 9 & 100 \\
\hline
\end{tabular}

Entre as principais causas para a existência do risco de choque elétrico, destacam-se irregularidades em tomadas, sendo classificadas como "relevante", bem como o uso de adaptadores "benjamim" nas mesmas, classificadas como "de atenção" pelo fato de existirem partes vivas expostas ou fios improvisados nos equipamentos e nas fiações elétricas das instalações, sendo classificado como "crítica" (Figura 2).

Figura 2 - Instalações elétricas com risco: (a) tomadas irregulares, (b) fiações expostas, (c) partes vivas expostas no disjuntor e (d) equipamentos sem aterramento

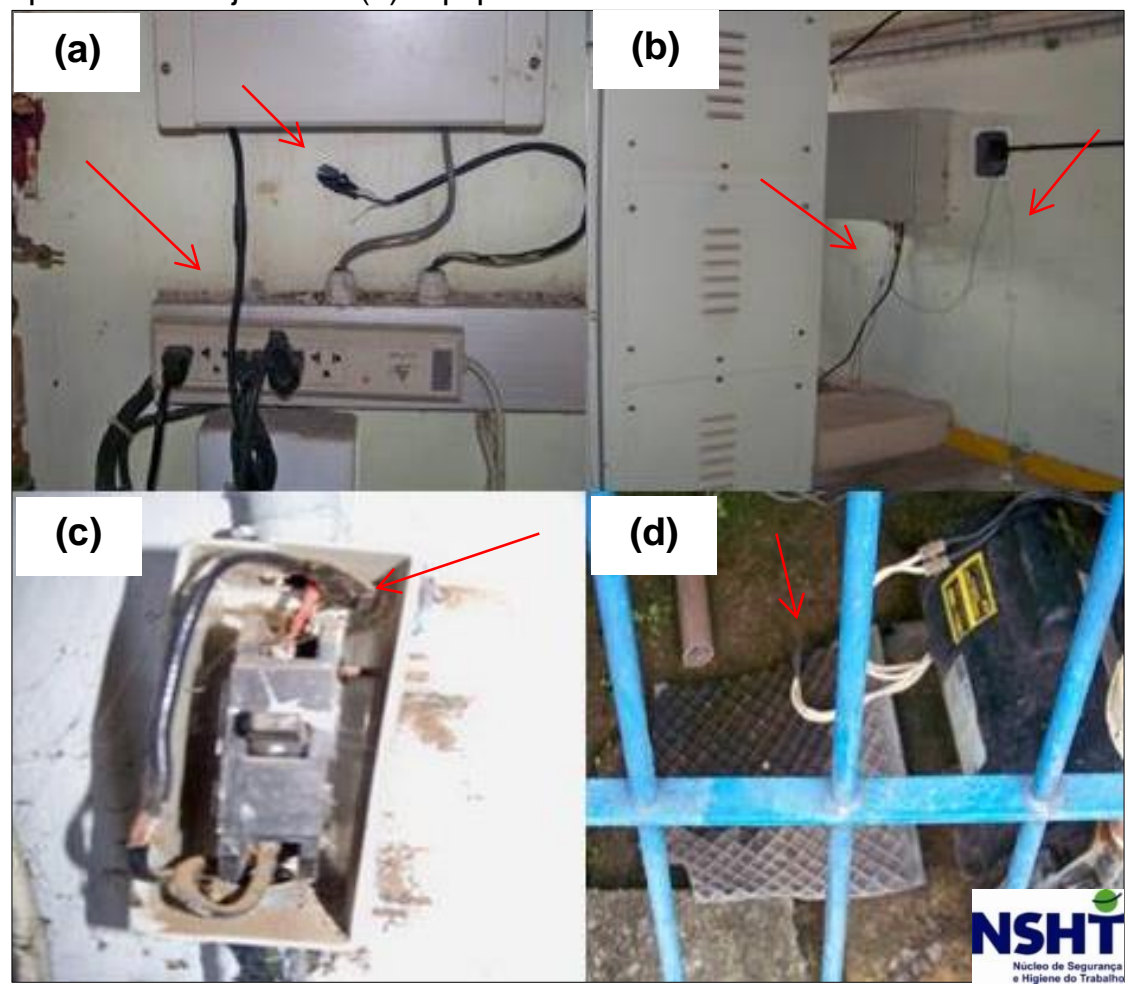

Fonte: NSHT (2014)

Também foi constatado o risco ergonômico de postura inadequada (Tabela 3) e em grande parte das unidades utilizadas neste estudo. 
Tabela 3 - Classificação do grau de risco de postura inadequada

\begin{tabular}{ccc}
\hline Grau de risco & EEA & $\%$ \\
\hline Irrelevante & 0 & 0 \\
Relevante & 6 & 75 \\
De Atenção & 2 & 25 \\
Crítico & 0 & 0 \\
Emergencial & 0 & 0 \\
Total & 8 & 100
\end{tabular}

A postura inadequada é proveniente das atividades de manobra em registro realizadas externamente ou internamente, que em alguns casos necessitam da utilização de esforço em posições desconfortáveis, sendo feitas algumas vezes ao dia (Figura 3). Porém, em alguns casos a exposição é menor e com espaço entre os intervalos de execução.

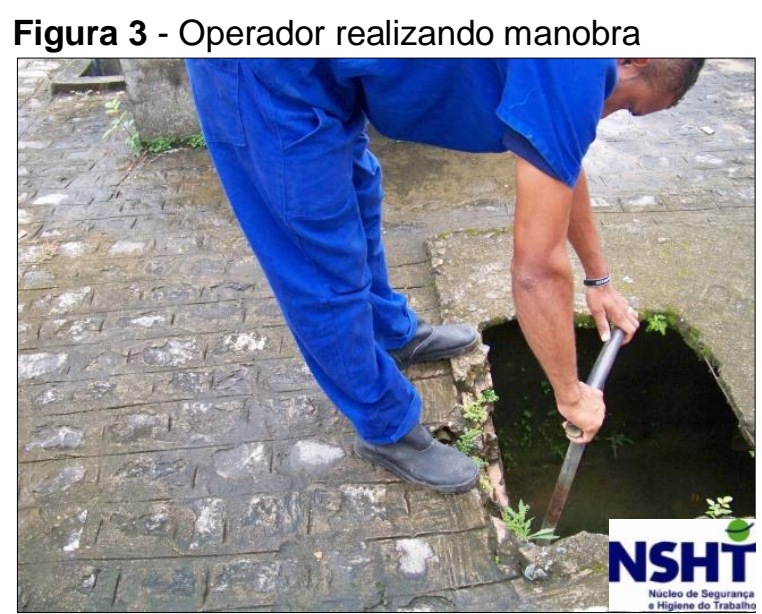

Fonte: NSHT (2014)

Além das manobras, a postura inadequada também está associada à de limpeza e manutenção das unidades, sendo realizada a varrição e a capinação do ambiente estudado, realizadas de forma eventual, não fazendo parte da rotina diária dos operadores.

A postura inadequada foi identificada nas atividades realizadas em 8 (oito) das 10 (dez) EEAs estudadas. Sendo classificadas nas categorias "relevante", com 6 (seis) estações, e "de atenção", com 2 (duas) estações, devido a posição dos equipamentos para realização da manobra. 
Quanto ao risco de queda, foi encontrado em $90 \%$ das unidades estudadas, dentre as quais, foi observado que 4 (quatro) delas apresentavam o risco classificado na categoria "de atenção" e 5 (cinco) na categoria "crítica" (Tabela 4).

Tabela 4 - Classificação do grau de risco de queda

\begin{tabular}{ccc}
\hline Grau de risco & EEA & $\%$ \\
\hline Irrelevante & 0 & 0 \\
Relevante & 0 & 0 \\
De Atenção & 4 & 44 \\
Crítico & 5 & 56 \\
Emergencial & 0 & 0 \\
Total & 9 & 100 \\
\hline
\end{tabular}

Sendo considerada "de atenção" quando se tratou de pequenas irregularidades e com frequencia moderada de exposição, como os desníveis existentes no terreno nas edificações e pequenas aberturas de piso sem proteção nas unidades e/ou pela existência de pequenas irregularidades em escadas com menos de 2,00 (dois) metros de altura (Figura 4).

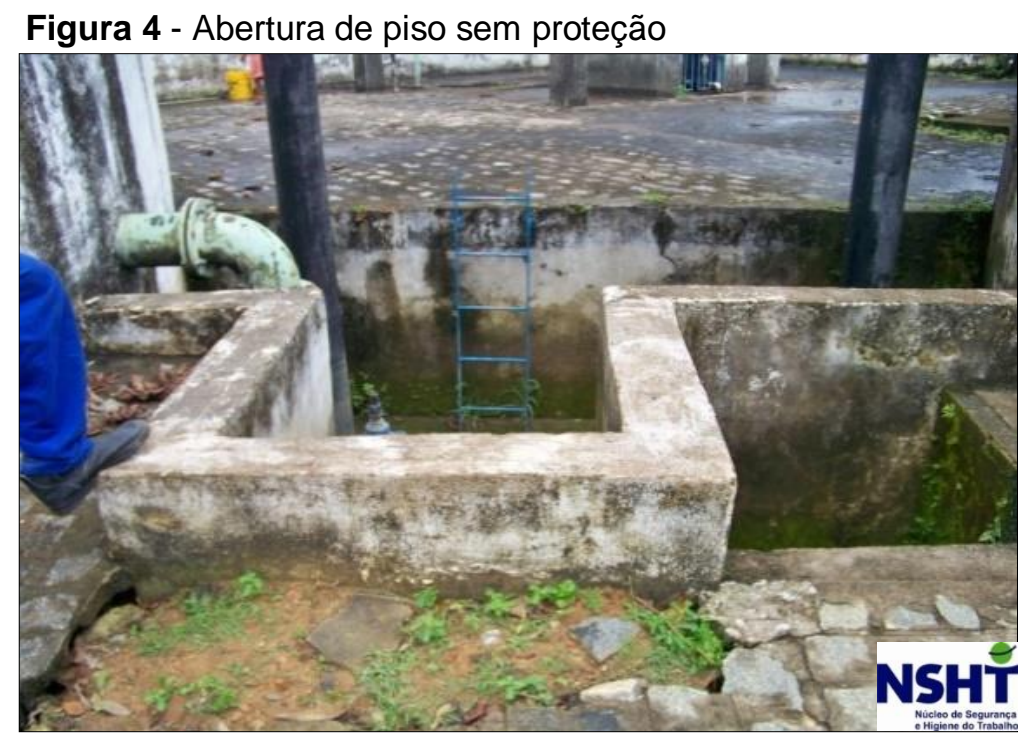

Fonte: NSHT (2014)

Da mesma forma, a categoria "crítica" representa a existência de vão de acesso para a realização de manobras, no qual os operadores necessitam realizar diariamente, não possuir guarda corpo, bem como, as escadas, com altura a partir de 2,00 (dois) metros, que dão acesso a sala onde se localizam os CMBs não possuírem proteção contra quedas (Figura 5). 
Figura 5 - Escadas sem gaiola de proteção

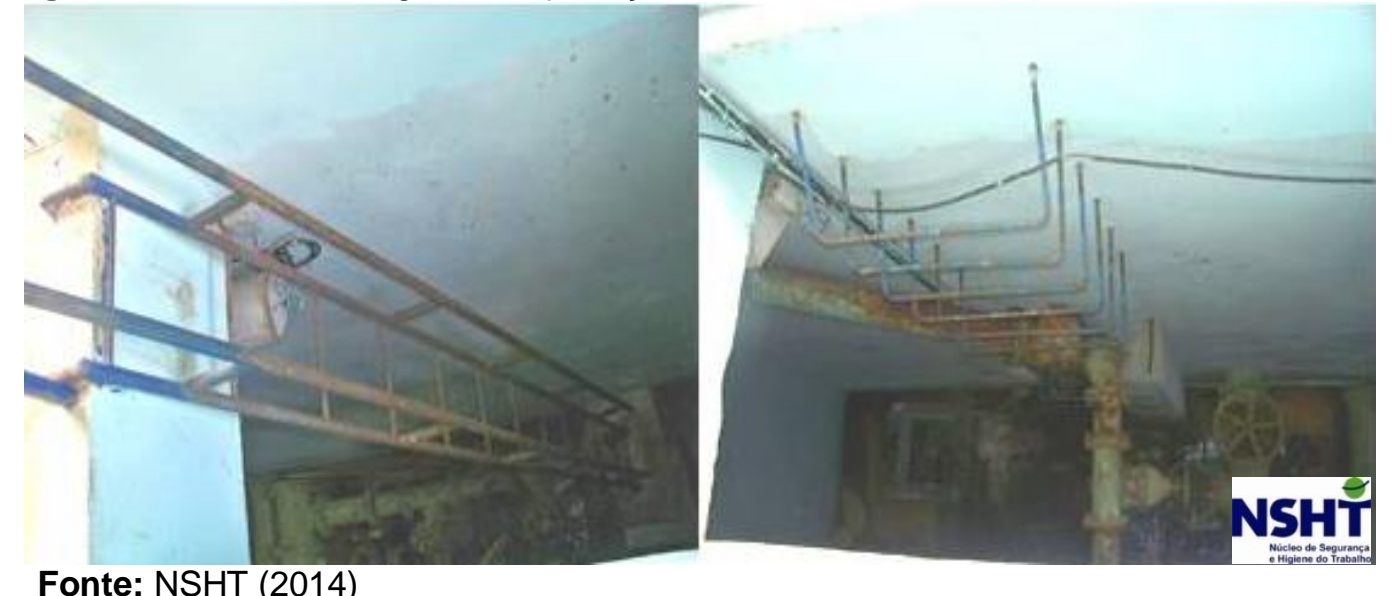

O risco de acidente de picada de animais peçonhentos, também foi identificado nas Estações Elevatórias de Água, encontrado em 40\% destas. Devendo-se ao fato das unidades apresentarem condições para a proliferação desses animais, contendo mato e resíduos da construção espalhados pelo terreno, sendo desta forma, classificado na categoria "de atenção" (Tabela 5).

Tabela 5 - Classificação do grau de risco de picada de animais peçonhentos

\begin{tabular}{ccc}
\hline Grau de risco & EEA & $\%$ \\
\hline Irrelevante & 0 & 0 \\
Relevante & 0 & 0 \\
De Atenção & 4 & 100 \\
Crítico & 0 & 0 \\
Emergencial & 0 & 0 \\
Total & 4 & 100 \\
\hline
\end{tabular}

O risco de acidente de prensamento foi identificado em $30 \%$ das unidades analisadas (Tabela 6). Este advém da existência de partes móveis desprotegidas nos equipamentos do CMB (Figura 6) sendo classificada como "crítico" por se tratar de exposição moderada ao agente e este causar efeitos severos.

Tabela 6 - Classificação do grau de risco de prensamento

\begin{tabular}{ccc}
\hline Grau de risco & EEA & $\%$ \\
\hline Irrelevante & 0 & 0 \\
Relevante & 0 & 0 \\
De Atenção & 3 & 100 \\
Crítico & 0 & 0 \\
Emergencial & 0 & 0 \\
Total & 3 & 100 \\
\hline
\end{tabular}


Figura 6 - Eixo localizado entre a bomba e o motor sem carcaça de proteção

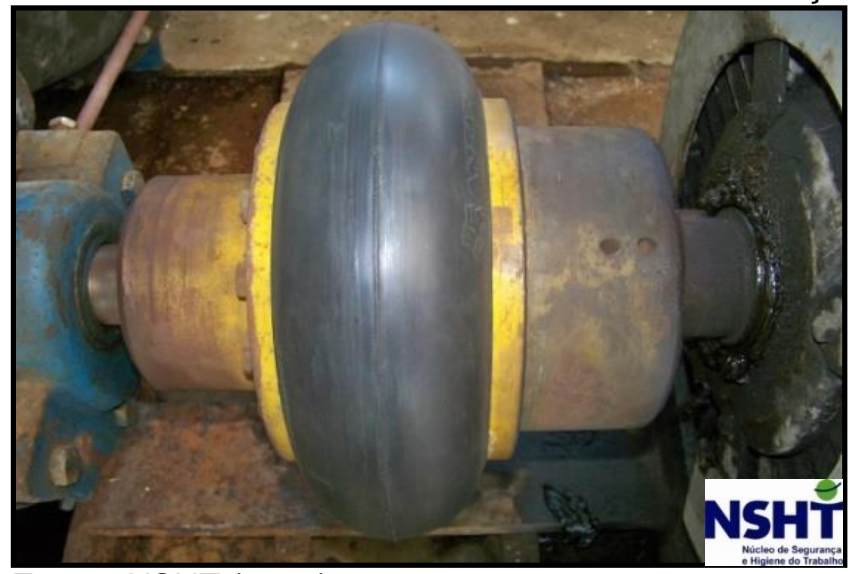

Fonte: NSHT (2014)

O risco de acidente de trânsito foi identificado em $20 \%$ das unidades de Estações Elevatória de Água analisadas (Tabela 7). Este foi classificado na categoria "de atenção", devido à frequência da exposição. Ocorrendo nos casos em que os operadores volantes se direcionam para as estações que não possuem operador fixo, através de veículos da empresa.

Tabela 7 - Classificação do grau de risco de acidente de trânsito

\begin{tabular}{ccc}
\hline Grau de risco & EEA & $\%$ \\
\hline Irrelevante & 0 & 0 \\
Relevante & 0 & 0 \\
De Atenção & 2 & 100 \\
Crítico & 0 & 0 \\
Emergencial & 0 & 0 \\
Total & 2 & 100 \\
\hline
\end{tabular}

\subsection{Análise sistemática}

Na sequência, foi elaborada uma Análise Preliminar dos Riscos - APR, considerando o tratamento para os riscos avaliados e classificados, quanto ao seu grau de risco, o qual leva em consideração a exposição ao risco e o efeito à saúde. No tratamento foi abordado de que formas a prevenção e a proteção podem atuar para diminuição e eliminação dos riscos ao quais os operadores destes ambientes estão expostos. Desta forma, foi realizado o levantamento da relação do risco com a causa, o efeito, a classificação do risco e o tratamento (Quadro 8). 
Quadro 8 - Análise preliminar dos riscos para a função de operador de estação elevatória (continua)

\begin{tabular}{|c|c|c|c|c|}
\hline Risco & Causa & Efeito & $\begin{array}{c}\text { Classificação } \\
\text { do Risco }\end{array}$ & Tratamento \\
\hline \multicolumn{5}{|c|}{ Ergonômico } \\
\hline $\begin{array}{c}\text { Postura } \\
\text { inadequada }\end{array}$ & $\begin{array}{l}\text { Manobras; } \\
\text { Limpeza e } \\
\text { manutenção da } \\
\text { unidade } \\
\text { (capinação e } \\
\text { varrição). }\end{array}$ & $\begin{array}{l}\text { Lombalgias; } \\
\text { Fadigas } \\
\text { muscular e } \\
\text { mental. }\end{array}$ & $\begin{array}{l}\text { Relevante; } \\
\text { De atenção. }\end{array}$ & $\begin{array}{l}\text { Correção dos locais } \\
\text { de trabalho; } \\
\text { Automatização do } \\
\text { sistema de } \\
\text { execução de } \\
\text { manobras; } \\
\text { Utilização de } \\
\text { máquinas para } \\
\text { capinação. }\end{array}$ \\
\hline \multicolumn{5}{|c|}{ Acidente } \\
\hline $\begin{array}{l}\text { Choque } \\
\text { elétrico }\end{array}$ & $\begin{array}{c}\text { Partes vivas } \\
\text { expostas em } \\
\text { tomadas, } \\
\text { disjuntores e } \\
\text { quadros de } \\
\text { comando; } \\
\text { Instalações } \\
\text { elétricas das } \\
\text { edificações e dos } \\
\text { equipamentos sem } \\
\text { tubos eletrodutos e } \\
\text { expostas às } \\
\text { intempéries; } \\
\text { Quadros de } \\
\text { comando sem } \\
\text { identificação e } \\
\text { avisos; } \\
\text { Equipamentos sem } \\
\text { aterramento } \\
\text { (CMB). }\end{array}$ & $\begin{array}{l}\text { Eletrocussão; } \\
\text { Queimaduras; } \\
\text { Sequelas } \\
\text { diversas. }\end{array}$ & $\begin{array}{l}\text { De atenção; } \\
\text { Crítico. }\end{array}$ & $\begin{array}{l}\text { Aterramento dos } \\
\text { equipamentos; } \\
\text { Manutenção } \\
\text { periódica das } \\
\text { instalações } \\
\text { elétricas; Emprego } \\
\text { de placas de } \\
\text { sinalização de } \\
\text { perigo; Uso de } \\
\text { botas com } \\
\text { biqueiras de PVC. }\end{array}$ \\
\hline Queda & $\begin{array}{l}\text { Pisos } \\
\text { desnivelados; } \\
\text { Escadas sem } \\
\text { corrimão e guarda } \\
\text { corpo; Aberturas } \\
\text { no piso sem } \\
\text { proteção; } \\
\text { Periferias e } \\
\text { passarelas com } \\
\text { mais de } 2 \mathrm{~m} \text { de } \\
\text { altura sem } \\
\text { proteção; Escadas } \\
\text { improvisadas; } \\
\text { Escadas de } \\
\text { acesso a } \\
\text { reservatórios sem } \\
\text { fixação. }\end{array}$ & $\begin{array}{l}\text { Morte; } \\
\text { Fraturas } \\
\text { leves e } \\
\text { graves. }\end{array}$ & $\begin{array}{l}\text { Relevante; } \\
\text { De atenção; } \\
\text { Crítico. }\end{array}$ & $\begin{array}{l}\text { Implantar gaiola de } \\
\text { proteção nas } \\
\text { escadas coletivas } \\
\text { com mais de } 2 \mathrm{~m} ; \\
\text { Construir } \\
\text { instalações com } \\
\text { pisos nivelados; } \\
\text { Fechar as } \\
\text { aberturas de piso } \\
\text { ou colocar } \\
\text { proteção; } \\
\text { Substituição das } \\
\text { escadas } \\
\text { danificadas. }\end{array}$ \\
\hline
\end{tabular}


Quadro 8 - Análise preliminar dos riscos para a função de operador de estação elevatória (conclusão)

\begin{tabular}{|c|c|c|c|c|}
\hline Risco & Causa & Efeito & $\begin{array}{c}\text { Classificação } \\
\text { do Risco }\end{array}$ & Tratamento \\
\hline \multicolumn{5}{|c|}{ Acidente } \\
\hline $\begin{array}{l}\text { Picada de } \\
\text { animais } \\
\text { peçonhentos }\end{array}$ & $\begin{array}{l}\text { Vegetação e } \\
\text { entulho ao redor } \\
\text { da unidade. }\end{array}$ & $\begin{array}{l}\text { Asfixia; } \\
\text { Câimbras; } \\
\text { Inchaço; } \\
\text { Náusea; } \\
\text { Morte. }\end{array}$ & De atenção & $\begin{array}{l}\text { Realizar limpeza no } \\
\text { terreno; } \\
\text { Dedetização } \\
\text { periódica. }\end{array}$ \\
\hline Prensamento & $\begin{array}{l}\text { Partes móveis } \\
\text { desprotegidas no } \\
\text { CMB. }\end{array}$ & $\begin{array}{l}\text { Lesões; } \\
\text { Fraturas; } \\
\text { Perda de } \\
\text { membros. }\end{array}$ & De atenção & $\begin{array}{l}\text { Instalação de } \\
\text { carcaças de } \\
\text { proteção nos eixos } \\
\text { de conexão entre a } \\
\text { bomba e o rotor. }\end{array}$ \\
\hline $\begin{array}{l}\text { Acidente de } \\
\text { trânsito }\end{array}$ & $\begin{array}{l}\text { Utilização do } \\
\text { veículo para } \\
\text { realização serviços } \\
\text { em outras } \\
\text { unidades. }\end{array}$ & $\begin{array}{l}\text { Lesões } \\
\text { diversas }\end{array}$ & Relevante & $\begin{array}{l}\text { Ter atenção ao } \\
\text { utilizar o veículo } \\
\text { para se deslocar } \\
\text { nas operações } \\
\text { como volante; } \\
\text { Utilizar sempre o } \\
\text { cinto de segurança. }\end{array}$ \\
\hline
\end{tabular}

A partir da implementação da APR, foi possível notar que, no que se refere ao risco ergonômico postura inadequada, encontrada na realização das atividades de manobras, realizadas com mais frequência, e limpeza e manutenção das unidades, realizadas esporadicamente, medidas como correção dos locais de trabalho, levando em consideração como posto de trabalho o volante (registro) utilizado para a realização da mesma. Ainda, sobre as manobras, outra alternativa é a implantação de sistema automatizado para a realização da mesma, sendo necessário apenas que operador acione através de comando eletrônico.

Para a capinação e varrição, atividades presentes na execução da limpeza e manutenção, devem ser levadas em consideração a postura do operador na realização destas tarefas e as ferramentas utilizadas pelo mesmo. Podendo em alguns casos, dependendo da localização e da situação da vegetação, disponibilizar máquinas para a execução dessas atividades, como roçadeiras e aparadores.

Em relação ao risco de acidente, o choque elétrico, que através do estudo foi possível identificar sua existência através de partes vivas expostas em tomadas, disjuntores e quadros de comando; instalações elétricas das edificações e dos equipamentos sem tubos eletrodutos, que em alguns casos, se encontravam expostas às intempéries, quadros de comando sem identificação e avisos de perigo 
e do risco de choque elétrico; e por equipamentos e máquinas sem aterramento, como o conjunto motor bomba e quadros de comando.

As medidas mitigadoras que podem ser adotadas nos casos encontrados nas unidades, citados no parágrafo anterior, incluem o aterramento elétrico dos equipamentos e máquinas, isto é, Quadros de Comando, Subestações e as grades utilizadas na cerca das mesmas, e CMBs. Quanto às partes vivas expostas em diversos equipamentos, fiações e tomadas, devem ser concertadas através de protetores, como caixas protetoras e tubos eletrodutos e, caso necessário, devem ser substituídas.

Os equipamentos que oferecem risco de choque elétrico devem conter placas de sinalização contendo informações quanto ao perigo da eletricidade e ao risco de acidente. Além de informar se deve ser utilizado algum equipamento de proteção para utilização do mesmo.

Além das substituições e correções, faz-se necessário que, estas instalações sejam monitoradas regularmente, e posteriormente corrigidas, quando novamente, surgirem situações que possam gerar risco.

Em relação ao risco de queda, identificada na maioria das unidades estudadas, caracterizada pela existência de pisos desnivelados, escadas sem corrimão, aberturas no piso sem proteção, periferias e passarelas com mais de 2,00 (dois) metros de altura sem proteção, escadas improvisadas e escadas de acesso a reservatórios e filtros sem fixação.

Estes requerem tratamento, que podem ser feitos através da implantação de correção dos desnivelamentos existentes nos pisos das estações, encontrados principalmente na casa de bombas. Bem como, realizar o fechamento das aberturas de piso ou colocar proteção, instalação escadas em boas condições de uso, com corrimão e proteção contra queda dos dois lados, além de, utilizar escadas tipo marinheiro com gaiola de proteção, a partir da altura de 2,00 (dois) metros principalmente nos reservatórios elevados.

Para o risco de picadas de animais peçonhentos, medidas apenas de manutenção do ambiente podem diminuir a probabilidade de ocorrer um acidente, como a limpeza no terreno e a dedetização periódica. Como em sua grande maioria, a manutenção e a limpeza da unidade, dependem do próprio operador para serem 
realizadas, sugerem-se que o mesmo utilize equipamentos de proteção, como botas de PVC cano alto e perneiras.

Quanto ao risco de prensamento, que pode ser causado por partes móveis desprotegidas no CMB das Estações Elevatórias de Água, deve ser tratado com a instalação de carcaças de proteção nos eixos de conexão entre a bomba e o rotor.

Com relação ao risco de acidente de trânsito, detectado na realização da atividade de operação volante, onde o operador necessita utilizar o veículo para se deslocar até outras unidades que não possuem operador fixo, recomenda-se como medida mitigadora a atenção na direção do veículo, bem como a utilização do cinto de segurança.

\section{CONSIDERAÇÕES FINAIS}

A partir da pesquisa realizada foi possível compreender o funcionamento das Estações Elevatórias de Água, bem como verificar, que estas instalações se caracterizam também por apresentar processos e ambientes que oferecem riscos de segurança do trabalho aos seus operadores.

Além disso, a partir do presente estudo foi possível identificar quais as principais atividades desenvolvidas pelos trabalhadores de Estações Elevatórias de Água, sendo estas, a limpeza e manutenção da unidade, comunicação via rádio, controle do nível dos reservatórios, acionamento dos CMBs, realização de manobras de descarga e abertura de registro e elaboração de relatórios.

Desta forma, pode-se concluir que tais atividades nos ambientes estudados geram riscos de segurança, de postura inadequada, no que se refere ao risco ergonômico, e de queda, choque elétrico, picada de animais peçonhentos, prensamento e acidentes de trânsito, no que tange aos riscos de acidentes.

Contudo, após classificação dos riscos encontrados, em categorias (irrelevante, relevante, de atenção, crítica e emergencial), foi possível perceber que os riscos choque elétrico, além de ter sido encontrado em maior número de estações, também apresentou a classificação nos graus "de atenção" e "crítico".

O risco de queda, também esteve presente na maioria das estações, apenas 1 (uma) das 9 (nove) instalações, não teve este risco identificado, visto que se 
tratava de uma unidade que possuía operador volante. Além disso, este risco de acidente foi classificado nas categorias "relevantes", "de atenção" e "crítico".

Os demais riscos de acidentes, como picada de animais peçonhentos, prensamento e acidente de trânsito, foram classificados, respectivamente, como "de atenção" e "relevante".

Com a realização da Análise Preliminar de Riscos, foi possível detectar quais medidas podem ser adotadas, nesses ambientes, para prevenir e mitigar a existência dos riscos identificados, na atividade de operador de Estação Elevatória de Água.

Desse modo, compreende-se que a utilização sistemática de análises de risco pode, através da implantação das medidas citadas no capítulo anterior diminuir os riscos de acidentes e ou doenças em Estações Elevatórias de Água.

\section{REFERÊNCIAS}

ANTÃO. M. L.. Diagnóstico das condições de trabalho em altura e proposta de ferramentas de análise de risco. Recife, 2014, 152 p. Dissertação (Mestrado em Engenharia Civil) Escola Politécnica de Pernambuco. Universidade de Pernambuco.

BARKOKÉBAS JR, B.; VASCONCELOS, B. M.; LAGO, E. M. G.; MONTEIRO, M. M.; NÓBREGA, F. de C. Avaliação do ruído contínuo a que estão expostos os trabalhadores das estações elevatórias de água bruta de Pernambuco. In: X Safety, Health and Environment World Congress, 2010, São Paulo. SHEWC 2010. São Paulo: SHEWC, 2010.

BOUTELHIG, A.; ARAB, A. H.; HANINI, S.. New approach to exploit optimally the PV array output energy by maximizing the discharge rate of a directly-coupled photovoltaic water pumping system (DC/PVPS). Energy Conversion and Management, v. 111, p. 375-390, 2016. https://doi.org/10.1016/i.enconman.2015.12.058

BRAGA, Sérgio. Apostila de Gerenciamento de Riscos. Braga \& Bouwman. Engenharia e Consultoria Ltda. 2007.

CHIARA, José. Manual Técnico: Bombas e estações elevatórias utilizadas em abastecimento de água. 2.ed. São Paulo: EDUSP, 1968.

CRUZ, F. M.; LAGO, E. M. G.; BARKOKÉBAS JUNIOR, B. . Evaluation of noise generated by propagation equipment beat stakes construction site. In: Pedro Arezes; João Santos Baptista; Monica P. Barroso; Paula Carneiro; Patrício Cordeiro; Nelson Costa; Rui B. Melo; A. Sergio Miguel; Gonçalo Perestrelo. (Org.). Occupational Safety and Hygiene. 1ed.London: CRC Press, v. 1, p. 437-441, 2013. https://doi.org/10.1201/b14391-90

GUENAB, F.; BOULANGER, J. L.; SCHÖN, W. Safety of railway control systems: a new preliminary risk analysis approach. International journal of safety and security engineering, v. 3, n. 1, p. 59-68, 2013. 
GURGEL, B. B. F. A. Proposição de uma metodologia para avaliação de inversores de frequência em estações elevatórias de água, estudo de casos no sistema de abastecimento de água de São José dos Campos. São Paulo, 2006, 133 p. Dissertação (Mestrado em Engenharia) Escola Politécnica de São Paulo. Universidade de São Paulo. https://doi.org/10.11606/d.3.2006.tde-13032007-011128

HELLER, Leo; PÁDUA, Valter Lucio. Abastecimento de água para consumo humano. Belo Horizonte-, MG, Ed. UFMG, 2006. 859p.

HERNANDEZ, D. V.; MAC, R. Electrical hazard prevention program at a water and wastewater utility. In: Electrical Safety Workshop (ESW), 2016 IEEE IAS. IEEE, 2016. p. 17. https://doi.org/10.1109/esw.2016.7499704

KOHLMAN RABBANI, E. R.; BARKOKÉBAS JR. B.; Lago, E. M. G.; VASCONCELOS, B. M.; CERQUEIRA, C. A.; SANTOS, F. J. B. Avaliação do ruído ocupacional e proposição de estratégia para determinação de proteção auricular: estudo em estações elevatórias no Brasil. In: International Symposium on Occupational Safety and Hygiene. SHO, 2011, Guimarães. Proceedings. Guimarães: Sociedade Portuguesa de Segurança e Higiene Ocupacional - SPOSHO, 2011. p. 529-533. Disponível em: < http://pessoais.dps.uminho.pt/parezes/downloads/sho2011.pdf> Acesso em: 26 jan. 2016.

LAGO, E. M. G. ; BARKOKÉBAS JUNIOR, B. ; KOHLMAN RABBANI, E. R.; VERAS, J. C ; SILVA, T. R. F. Indicadores de gestão de segurança em uma indústria de cimento. In: XXVIII Encontro Nacional de Engenharia de Produção, 2008, Rio de Janeiro. A Integração em Cadeias Produtivas com a Abordagem da Manufatura Sustentável. Rio de Janeiro: Associação Brasileira de Engenharia de Produção, 2008.

MAHAR, P. S.; SINGH, R. P. Optimal design of pumping mains considering pump characteristics. Journal of Pipeline Systems Engineering and Practice, v. 5, n. 1, p. 04013010, 2013. https://doi.org/10.1061/(ASCE)PS.1949-1204.0000157

MCCARROLL, K. R., LEE, J. C., MANERA, A., MEMMOTT, M. J., \& FERRONI, P.. Preliminary risk assessment of the Integral Inherently-Safe Light Water Reactor. Annals of Nuclear Energy, 2016.

NUCASE. Núcleo Sudeste de Capacitação e Extensão Tecnológica em Saneamento Ambiental. Saúde e segurança do trabalho aplicado ao gerenciamento de resíduos sólidos. 2008. Disponível em: <http//: nucase.desa.ufmg.br/wpcontent/uploads/2013/08/RSU-SST.1.pdf>. Acesso em: 01 de junho 2016.

OLIVEIRA, B. L. Estações Elevatórias características construtivas e geração de ruído. Campinas, 2010, 265 p. Dissertação (Mestrado em Engenharia Civil). Faculdade de Engenharia Civil, Arquitetura e Urbanismo. Universidade Estadual de Campinas.

RAWAT, R.; KAUSHIK, S. C.; LAMBA, R. A review on modeling, design methodology and size optimization of photovoltaic based water pumping, standalone and grid connected system. Renewable and Sustainable Energy Reviews, v. 57, p. 1506-1519, 2016. https://doi.org/10.1016/j.rser.2015.12.228

SANESUL. EMPRESA DE SANEAMENTO DE MATO GROSSO DO SUL S.A. (2011) Disponível em: < http://www.sanesul.ms.gov.br/>. Acesso em: 19 abr. 2015. 
SANTOS, L. P. S.; SOARES, A. K.; SILVA, S. S. Eficiência hidroenergética em sistemas de distribuição de água: uma discussão teórica, p. 383-392 . In: Anais do XIV Encontro Nacional de Estudantes de Engenharia Ambiental. Blucher Engineering Proceedings v. 3 n.2. São Paulo: Blucher, 2016. ISSN 2357-7592, DOI 10.5151/engpro-eneeamb2016-rh-0154842.

TSUTIYA, M. T. Utilização de inversores de frequência para diminuição do consumo de energia elétrica em sistemas de bombeamento. IV SEREA - Seminário Iberoamericano sobre sistemas de abastecimento urbano de água. João Pessoa, Paraíba. 2006.

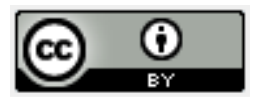

Artigo recebido em 24/02/2016 e aceito para publicação em 15/12/2016

DOI: http://dx.doi.org/10.14488/1676-1901.v17i1.2369 